\title{
Conversation
}

\section{A conversation about implicit bias}

\author{
Amanda L. Golbeck ${ }^{\mathrm{a}, *}$, Arlene Ash ${ }^{\mathrm{b}}$, Mary Gray ${ }^{\mathrm{c}}$, Marcia Gumpertz ${ }^{\mathrm{d}}$, Nicholas P. Jewell ${ }^{\mathrm{e}}$, \\ Jon R. Kettenring ${ }^{\mathrm{f}}$, Judith D. Singerg ${ }^{\mathrm{g}}$ and Yulia R. Gel ${ }^{\mathrm{h}}$ \\ ${ }^{a}$ Fay W. Boozman College of Public Health, University of Arkansas for Medical Sciences, Little Rock, AR, USA \\ ${ }^{\mathrm{b}}$ Department of Quantitative Health Sciences, University of Massachusetts Medical School, Worchester, MA, USA \\ ${ }^{\mathrm{c}}$ Department of Mathematics and Statistics, American University, Washington, DC, USA \\ ${ }^{\mathrm{d}}$ Office of the Provost, North Carolina State University, Raleigh, NC, USA \\ ${ }^{\mathrm{e}}$ Department of Biostatistics, School of Public Health, University of California - Berkeley, Berkeley, CA, USA \\ ${ }^{\mathrm{f}}$ Research Institute for Scientists Emeriti, Drew University, Madison, NJ, USA \\ ${ }^{\mathrm{O}}$ Office of the Provost, Harvard University, Cambridge, MA, USA \\ ${ }^{\mathrm{h}}$ Department of Mathematical Sciences, University of Texas - Dallas, Richardson, TX, USA
}

\begin{abstract}
Explicit bias reflects our perceptions at a conscious level. In contrast, implicit bias is unintentional and operates at a level below our conscious awareness. Implicit stereotypes shaping implicit biases are widely studied in criminal justice, medicine, CEO selection at Fortune 500 companies, etc. However, the problem of unconscious bias remains. E.g., while women constitute an increasing proportion of all STEM undergraduates, they still make up only a small proportion of faculty members at research universities, and they are substantially under-represented in organizational leadership and as recipients of professional awards and prizes. Can we afford to have unintentional perceptions continue to hinder the success and advancement of women and other underrepresented groups? Can we afford to continue to underuse human capital in science? This session at the 2015 Joint Statistical Meetings (JSM) aimed to illuminate what statisticians need to know and do to break the glass ceiling of implicit bias.
\end{abstract}

Keywords: Stereotypes, leadership, awards, women, minorities

\section{Introduction}

Golbeck: Why did I want to organize a session at the JSM on "Implicit Bias: What Statisticians Need to Know and Do"? I will answer this question with three stories.

One relates to a video. In the late 1990's, one of my responsibilities was to direct a university-wide mentoring program. I hired a diversity trainer who brought in a video, The Color of Fear [33], which captured deep conversations about race among men gathered for a weekend retreat. We watched as the men discovered racist attitudes they didn't know they had. It was powerful.

\footnotetext{
*Corresponding author: Amanda L. Golbeck, Fay W. Boozman College of Public Health, University of Arkansas for Medical Sciences, 4301 West Markham, \#820, Little Rock, AR 72201, USA. Tel.: +1 501526 6611; E-mail: agolbeck@uams.edu.
}

A second story relates to an interview. A few years ago in relationship to a microhistory project, I interviewed a former UC-Berkeley law school dean, Sanford Kadish. The background is that, in 1968 at Berkeley, only $3 \%$ of tenure ladder faculty members were women, and $44 \%$ of departments had gone over 50 years without having even one tenured woman. I asked Kadish why it was that Berkeley first took up the issue of equal employment opportunity for women in 1968. He said, "Academic senate policy committee members were so busy thinking about discrimination against ethnic minorities that they just hadn't ever given thought to discrimination against women" [11].

A third story relates to the JSM Registration Guide. When I received my guide in 2012, I noticed there were no pictures of women in it [10]. In 2013, I noticed that, of the 15 JSM keynote speakers, only one - the American Statistical Association (ASA) president - was a 


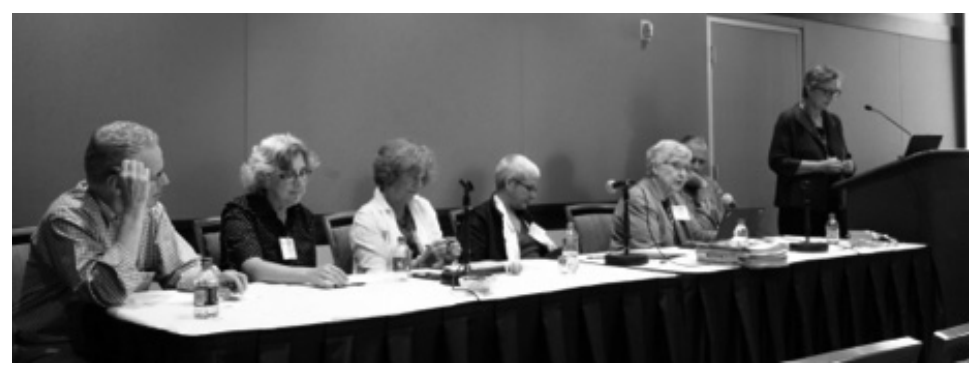

Fig. 1. The Panel (1 to r): Jon Kettenring, Marcia Gumpertz, Arlene Ash, Judy Singer, Mary Gray, Nick Jewell, Amanda Golbeck (moderator). Photo credit: Yulia R. Gel.

woman. Yet, about one third of ASA members were women.

When I brought the pictures issue to the attention of ASA leaders in 2012, they invited me to attend a national meeting of the AWARDS project in which they were participating. "AWARDS" is an acronym for Advancing Ways of Awarding Recognition in Disciplinary Societies. The National Science Foundation (NSF) funded this project in collaboration with the Association for Women in Science (AWIS). The question for the ASA was, if one third of members are women, then why don't one third of the ASA awards for research go to women? AWARDS focused on the role that implicit bias plays in the underrepresentation of women among research award winners [2].

AWARDS put a name to what I saw in the video, interview, and JSM Registration Guides. It was implicit bias.

Unfortunately, implicit bias problems for women and other underrepresented groups have been around for a long time. For example, in 1984 the late UCBerkeley Statistics Professor Elizabeth L. Scott looked at the percentages of NSF fellowships to women. She noticed that women won few such awards and wrote: "I wonder what is happening. There must be many different committees (panels) ranking the applicants in the different fields. Why is it that women are still coming out so poorly in the percentage of awards? Have there been some studies made that help to explain ... these striking differences in the probability of obtaining an NSF Fellowship, once you apply"? [28].

Yulia Gel (University of Texas-Dallas) and I (University of Arkansas for Medical Sciences) organized the JSM panel on implicit bias because we want our statistics organizations to be big tents for statisticians of all areas of practice, both genders, and all races and ethnicities. We want the same for our workplaces.

We invited to the panel ASA Fellows Arlene Ash (University of Massachusetts Medical School), Mary Gray (American University), Marcia Gumpertz (North
Carolina State University), Nick Jewell (University of California-Berkeley), Jon Kettenring (Drew University), and Judy Singer (Harvard University) (Fig. 1). These are statistician-leaders who have thought, and continue to think, deeply about implicit bias issues. Several are statistician-administrators who work out of provost's offices and specialize in issues of equity in employment. Sponsors of the session included the Caucus for Women in Statistics (the primary sponsor), Joint Committee on Women in the Mathematical Sciences, International Chinese Statistical Association, International Indian Statistical Association, Statistics Without Borders, ASA Section on Statistical Consulting, and ASA Scientific and Public Affairs Advisory Committee.

The panel organized around five primary questions. These provided the framework for the session and the report that follows.

\section{What is the difference between implicit and explicit bias, and why do we care about bias in the profession?}

Golbeck: When I think about bias, I recall a paper that I discovered early in my career, "Bias in Analytic Research", where the author created a useful catalog of 35 biases that can distort the design, execution, analysis, or interpretation of research [26]. Implicit bias isn't in the catalog; there only are a couple of biases where you can surmise a connection with implicit bias. An example is: "Expectation bias. Observers may systematically err in measuring and recording observations so that they concur with prior expectations".

So we can't extract an easy definition of implicit bias from our own literature. Jon, you have examined the broader literature. Can you please tell us what you've found?

Kettenring: I'd first like to add to my credentials. I manage a group of about ten people that has been in ex- 
istence for about 35 years. Our group has had only one woman in 35 years, and she is now retired. So perhaps I should stop here!

Just to make sure we are all on the same footing, let me start with some basic ideas of implicit bias. One of the things I ran across in preparing these remarks is a large study from Ohio State University by the Kirwan Institute for the Study of Race and Ethnicity [24]. My early comments will be based on what I found there. If you don't know it - and I did not - there is a rather large literature on the topic of implicit bias.

According to the Kirwan report, implicit bias refers to the attitudes or stereotypes that affect our understanding, actions, and decisions in an unconscious manner. Here the key word is unconscious. Some of the other things they emphasize that go beyond the unconscious and unintended are that the biases we are talking about are robust and pervasive, and we all - you and me - are susceptible to them.

On the other hand, at the other extreme, we have the explicit biases. These involve a higher degree of awareness. They may involve willful ignorance and blatant discrimination. These sorts of biases can be consciously detected and controlled, and some people claim they can be measured using various instruments.

As just a slight footnote, in thinking about these differences, the discrete separation between implicit and explicit may be more for our convenience than reality. Different ones of us would probably draw the line in different places.

Coming back to implicit bias, there has been a lot of research and debate on this topic for at least 30 years. Sometimes instead of using the term "implicit", you'll find people referring to it as unconscious bias, or some other similar term. Another label that is quite common is "automatic", as in instinctive or a gut reaction. So a lot of the implicit biases involve various types of stereotypes that we all no doubt have to some degree at least.

Some people have pointed to a connection in a modern book that many of you have probably read and I am presently reading. This is the book by the psychologist Daniel Kahneman, Thinking, Fast and Slow [18]. The thinking fast part of it ties in very nicely to the issue of implicit bias. The most common context for the various studies that I have seen involves implicit bias for women and minorities. But if you think about it for a minute there are lots of other potential applications that are perhaps less noteworthy: rich versus poor, old versus young, and so on. The Kirwan report that I referred to earlier talks about implicit biases concerning racial disparities that arise in our educational system, the judicial system, and the health system. In a recent issue of Science [29], I noticed a very interesting article that talked about cognitive bias on the part of forensic scientists. My take on it is that this is just another example of implicit bias.

Why do we care about implicit bias in the profession? I think the reasons are pretty obvious. I will mention a few. Implicit biases impact how we deal with one another, and the decisions that we makedecisions about hiring, pay, admissions, promotions, awards, committee assignments ... much of what we do as professional statisticians. The bottom line is that these implicit biases can result in poor decisionmaking, and consequentially generate all kinds of inefficiencies and distortions that we should not tolerate, and we really can't afford to have them.

Golbeck: Arlene, thinking as a statistician, you've noticed a possible relationship between implicit bias and Bayesian logic. Is implicit bias just Bayesian logic and, if so, what can we do about it?

Ash: Our society has similar numbers of men and women but more male scientists than female scientists. So the probability of being a scientist is higher for a man than for a woman, and - especially in fields where there are very few women - it's "natural" (Bayesian) to think "scientist $\rightarrow$ male". OK, scientists today are more likely to be men, but what does that tell you about whether, between comparably credentialed people applying for a job, one male and the other female, one has a higher probability of being a good scientist? Or whether the inquisitive little girl is more or less capable of becoming a great scientist as the inquisitive little boy? Understanding Bayes' theorem can help explain why people might bring automatic prejudices to situations in which they are unhelpful. I liked the following advice that emerged during the e-mail exchanges that preceded this panel: "If you are not confident about the suitability of an apparently well-qualified individual candidate, ask yourself, 'Why"'?

Golbeck: Marcia, we're hearing a lot about microaggressions today in the field of psychology. What are microaggressions, and speaking generally, what can be their cumulative effects on individuals in the profession who experience them?

Gumpertz: Microaggressions are the manifestations of unconscious bias. People have different ideas, as Jon said, about where the line is drawn between implicit and explicit bias, but in any case microaggressions can be very tiny things. The word sounds aggressive, but microaggressions aren't necessarily hos- 
tile or confrontational. Often they are just small slights, or little things that people say, and people aren't really aware that they're doing them or saying them. You can be in a situation where somebody does something and you aren't really aware that it's happened, unless you're the recipient of it. Microaggressions can be hard for the recipient to talk about, because people might think they are just being too sensitive if they react to these kinds of things.

Let me tell you about a few of the kinds of things I'm talking about. This is a familiar scenario: A woman is in a meeting and says something, and somebody else interrupts or somebody right behind her says something else, and the conversation goes on and nobody ever acknowledges that she said anything. Or she says something and nobody picks up on it, and a little while later somebody else says essentially the same thing maybe a man says it - and then everybody realizes this is a wonderful idea. Another kind of microaggression occurs when someone comes into a room and looks around and says hello to everybody except the single person of color in the room. And another one - this is one a department head told me about - they had done a department climate survey, and in the survey somebody said there was a male faculty member in the department who always put his arm around the women faculty and staff, and the department head didn't know what to do about it.

The recipient of a microaggression often doesn't want to say anything because others might just react by saying, "You're being too sensitive, you should just ignore it and let it go by". That kind of reaction can also be viewed as a kind of microaggression, indicating that the confidant is not really listening to the recipient of the microaggression and doesn't believe their interpretation.

Why are these important? Well there are some groups of people who experience this kind of thing in many interactions, even on a daily basis. The impact builds up, so they become sensitized to it. Their reaction may be to say to themselves "I don't really want to deal with these people anymore" and to disengage. That is really destructive for the group and the organization, and it is destructive for the success of the person who is disengaging.

One important thing to me about microaggressions is to learn to recognize them. It is important to figure out ways to interrupt them if you see them happening when they are not happening to you. That's one thing. But really the first thing, and the big thing for me in my journey along this path, has been to recognize when
I am perpetrating some kind of microaggression, and just really seeing it. There are things that we all do, and it's not easy to realize you are actually doing these things. But that's the first step in changing how the department climate is, for example, in your organization.

Golbeck: So you are talking about taking things that are more in your subconscious and bringing them more into your conscious awareness.

Gumperz: Right.

Golbeck: Marcia has pointed out that microaggressions, which result from unconsious biases, can also be destructive for individuals. Nick, which do you think is more important in affecting the growth of women or underrepresented minorities in an organization: Is it implicit bias or explicit bias?

Jewell: At first glance, I think most of us would agree that the consequences may be more extreme in cases of explicit bias, in terms of sexual harassment or overt discrimination, people losing their jobs, being damaged psychologically. But I think implicit biases are actually more difficult to deal with, and their consequences may be much more pervasive and destructive in the long run. That's worth thinking about, because we all feel strongly about blatant discrimination or illegal acts between men and women or people of different races. We believe laws should be enforced. But most people have a much weaker reaction to cases of implicit biases, as just indicated, when people tend to say: "You're being too sensitive, let it go, it doesn't matter". But there are consequences in the long run.

President Obama recently said in a renewed US conversation about race that the confederate flag should be taken down; he was urging its removal from the state capital in South Carolina. He went on to say that, while the confederate flag can be taken down, this doesn't mean it is gone from the heart. Obama's comments made it clear African-Americans generally appear to be much less happy and more dismayed about persistent implicit biases that they face every day than they are about people who obviously exhibit explicit biases towards them. While this might strike you as odd, it reflects how pervasive these implicit biases are and how deeply they are felt.

On a lighter note, you might wish to listen to a recent video interview (available online at https://www. youtube.com/watch? $\mathrm{v}=\mathrm{J}-\mathrm{VzAw} 2 \mathrm{HQq} 4$ ) between Kristen Stewart and Jessie Eisenberg, young actors in a current movie that Hollywood is advertising. They did a parody where they were going to interview each other to promote the movie. They flipped the cards and gave the 'woman' questions to Kristen to ask Jessie, and 
the 'men' questions to Jessie to ask Kristin. Jessie asks Kristen: "Tell me about how you were in high school, were you an actor, were you a class clown"? She answers that question very easily. Kristin turns to Jessie and says: "Are you in a relationship with someone right now? Are you pregnant"? He reacts: "That's a little personal, isn't it"? Then Jesse asks Kristin: "What is your favorite sports team"? She says "the Lakers". Then Kristin turns to Jesse and says: "Who designed your shirt"? He says: "I don't know, Levi? Who Cares"? As the interview proceeds, things get more heated, and finally Kristin turns to Jesse and says: "Now you know what it feels like to be a woman in Hollywood". This dialog prompts us to ask: What 'question cards' are you using when you look at someone's resume? What questions are you asking when you invite a speaker? What card deck are you using when you are voting for someone to get on a board? I think you'll be surprised at how significantly implicit biases are affecting the questions you are thinking of depending on the ethnicity, gender, or race of the person you are thinking about.

Golbeck: So far we've heard some of the everyday perspectives on implicit bias, but there may also be legal perspectives. Mary, you are both a statistician and an attorney. What would you say are the legal perspectives on implicit bias?

Gray: I'm not convinced there is a difference between implicit bias and explicit bias - so I probably don't belong on this panel! It seems to me the effect is the same no matter what the kind of bias. It is not good.

What about legal implications, then? There is a concept in law that is somewhat similar to implicit bias, and that's the issue of apparent discrimination in "disparate treatment and disparate impact", both of which are illegal [15].

Disparate treatment is: I'm not hiring or promoting you because you are a woman, or because of your race or some other reason.

Then there's disparate impact. The most recent US Supreme Court case that had to do with disparate impact was a United Parcel Service (UPS) case involving pregnancy rather than sex per se. The UPS had a rule that you couldn't be a driver if you couldn't lift 50pound weights, because you had to deliver the packages. As a result, when a woman was pregnant, and her doctor told her she couldn't lift 50-pound weights (incidentally, think about how many of you can lift 50pound weights, particularly up over your head), she was put on unpaid leave. But when the case came to court, it turned out the heaviest package the USP ever had on these routes was 20 pounds. Therefore, the court decided this was not a reason for putting the pregnant woman on unpaid leave. Going further back, there is a Supreme Court case that has to do with medical benefits, before we all had Affordable Health Care like we do now. What it said was: Not covering pregnancy benefits was OK, because pregnant men weren't covered either; this was discrimination on the basis of pregnancy, not discrimination on the basis of sex. We went through a round with pensions where there was discrimination on the basis of longevity rather than discrimination on the basis of sex. But they are all discrimination, and they are all bias, and the origin is the same.

Although we talk about disparate treatment and disparate impact, the impact is actually the same. It has a bad impact. So, the clarity that we get in the law is that both of these are illegal. This is the clarity that we need to understand in talking about implicit and explicit bias. The reason I said I don't see the difference is that I view implicit bias as a concept that someone came up with so you can show lots of slide shows to people about implicit bias, and then go away saying we have done something about bias. I sat through a number of these, one of which was with the ASA in how we select people for awards. There was some improvement as a result, but there is a tendency to slide back.

In fact, the tendency to slide back is something we all need to be cautious about. I was in a panel this past week in which we were talking about the percentage of PhD's in mathematics that go to women. It turns out that finally in 1988 we got back to where we were in 1930. It had gone down to $6 \%$ of PhD's in math being women at the time I got my $\mathrm{PhD}$, but it got back up to the low 20's by 1988, and it's gone up a little bit more now. Why? Because they have now included statistics in with math, and proportionately lots more women get PhD's in statistics than in math.

So, implicit or explicit, we need to worry about it.

\section{What are some concrete examples where you believe you've seen the effects of implicit bias on evaluations of women and underrepresented minorities?}

Golbeck: Next let's turn our attention to some 
concrete examples of implicit bias. Following the AWARDS meeting (that I mentioned earlier), I examined the ASA awards in more detail. From 2001 through 2012, the ASA gave seven types of research awards, and only $12 \%$ went to women, whereas $33 \%$ of ASA members were women. We do pretty well at selecting women to be presidents of the ASA, and fairly well at giving women awards for teaching and service, but we don't recognize enough women for their research [12]. There were no women at all among any of the Deming Lecturer Award winners. Likewise, no women won the Dixon Award for Excellence in Statistical Consulting. The research award bestowed most frequently on women was the Outstanding Statistical Application Award. But even there, only $16 \%$ of winners were women. It seemed to me that women did better at winning awards where the judgment was based on a particular paper or group of papers, as opposed to lifetime achievements.

Judy, what are some other examples of implicit bias on evaluations of women and underrepresented minorities?

Singer: To set the context, in addition to being a professor of statistics at Harvard University's Graduate School of Education, I am also the Senior Vice Provost for Faculty Development and Diversity for the entire university. In this role - which I've had for seven years - I oversee faculty affairs and academic appointments. Of particular importance to today's discussion, I participate in every tenure review. At Harvard, we solicit confidential letters about each potential tenured appointment from outside experts and also from the department or school's tenured faculty. I read all of these letters.

Let me give you a sense of what I sometimes see by sharing examples (each with identifying details changed to protect confidentiality). I keep these in a file labeled "outrageous letters".

- "I have serious concerns about the process in this search. The identities of the two finalists make it clear that the search was rigged from the start. How else could both be female"? As you might imagine, there are many searches in that department historically in which the two finalists have both been male. But to this senior faculty member, those could not have been rigged; only the search with two female finalists could be rigged.

- "The following anecdote makes me a bit unsure about our judgment. The last African-American candidate we interviewed was $\mathrm{X}$. The consensus then was that she did a very poor job field- ing questions and we wondered about her quality of mind. The paper she presented has since been published in [the top journal in the field]. Clearly she has been very successful at [University of Y] and in retrospect, I wish we had made her an offer". So they then tried to recruit her. And what did she do? She turned them down. Had she been appointed in the first place, they might have been successful at catching her at an earlier career stage.

- "She balances work and life in a way that detracts from her career". When you read confidential letters, you often find that women are nice, have children, and balance work and career. I'm confident that most of the people who write these things truly believe they're being helpful, but I'm here to say that they are not!

- "And what's more remarkable is that she did all of this while having three children". This sentence was particularly jarring because it's from a letter for a search in which we were recruiting a husband and wife, who also happen to write many papers together. Some external letter writers were asked to comment on only one of the candidates and a few were asked to comment on both. This particular letter writer made it very clear up front that when he was going to write about their "joint work" he would use the same paragraph, and when he was going to write about their separate work he would use different paragraphs. In the parallel paragraph about the husband, that included much of the same text, the letter writer didn't mention that "what's more remarkable is that he did all of this while having three children" - even though the wife's children are indeed also the husband's. If you were to draw conclusions about faculty demographics from reading confidential letters, you'd conclude that only women have children (as you rarely read about family matters in letters about men).

- "Her speech accepting the X award was the high note of the ceremony... eclectic, passionate, and well delivered; as well, her kimono was spectacular". Off-hand remarks like this serve to remind readers that the candidate is a woman and what she's wearing is important. On this point, here's another anecdote: I have two colleagues - one male, one female - who were invited to a major White House conference. We debriefed them about what happened at the White House and what kinds of questions they were asked when 
they were back on campus. The man was asked about which part of his excellent research he focused on. And what was the woman asked? What did she wear!

These examples are not the norm, but comments like these appear all too often. Implicit bias influences what people write and what people say more than most of us care to know.

Golbeck: There are so many areas in which we see these kinds of behaviors in the workplace. Marcia, Judy's examples had to do with faculty. I'm wondering if you could please provide some examples that have to do with students. Especially, what are the effects of implicit bias on academic advising?

Gumpertz: This topic is very important. There is a gap. I think that a good percentage of doctoral degrees in statistics are going to women. But then there is a drop in percentage of statistics faculty positions held by women. What I'm wondering about is the advising that the graduate students get about how to select their advisors and dissertation topics. In statistics, you can do many different kinds of dissertations, and they'll be suitable to prepare for a wide range of statistics career paths. I really have a question about whether women and minority students are being unconsciously steered toward nonacademic career options.

On the topic of selecting a major professor, an article came out recently looking at women in the biological sciences [30]. The authors examined the gender distribution of graduate students and postdocs who worked with faculty who had received prestigious awards. What they found was that the labs that were headed by prestigious male faculty trained a much smaller fraction of women than were in the graduate student population. In the biological sciences more than $50 \%$ of the PhDs go to women, but men with prestigious awards did not train nearly $50 \%$ women in their labs. In contrast, the women with prestigious awards did train a high fraction of women. This is important because a large number of people who go on to academic careers in these disciplines come out of these labs.

Golbeck: So we have heard about some examples of implicit bias that involve faculty and students. Nick, what can you tell us about the effects of implicit bias on selection of academic administrators?

Jewell: Since leaders set many policies for the rest of the community, implicit bias in the selection of administrators is a serious issue. I'd like to talk about my experience with leadership positions in higher education, where the situation may be much worse than in the private sector. Here I will present two symbolic cases concerning the appointment of university chancellors/presidents.

In the first case, a male told a story of his appointment as president of a very prominent public university. After he had been in his new position for several months, a regent who had served on the selection committee took him to lunch. This regent told the man that he had liked him instantly because he "looked like a president - you're tall - not like that short stubby guy [the other candidate]". So while it is generally understood that being tall as a man tends to make him more successful and attractive, it apparently sometimes is also the key to getting a university leadership position! One can only wonder how this regent was making other decisions, perhaps even more implicitly.

The second case has to do with the selection of a university chancellor - also at a leading public university. Two candidates, one male and one female, were asked a question about how they would handle a decision in the face of forcefully held and diametrically opposed opinions. A male regent indicated that they should select the man because his answer was to choose one position decisively, whereas the woman had suggested a more nuanced and cooperative approach: "She's going to compromise. You have to be decisive". The regent's response illustrates that the 'woman' answer can often be discredited by men because they simply "don't get it". We all suffer from this kind of implicit bias. We all often "don't get it".

These two cases refer to the choice of leaders of two major universities, people who are ultimately responsible for setting policies about promoting equity. These examples reflect the extraordinary uphill battle we have in rectifying the lack of women in leadership. Some countries have very family-friendly policies for women. Scandinavian countries have long had favorable policies for women, and they are much better places to work if you are a woman; but unfortunately they have no better record on having women in levels of leadership, like prime ministers and leaders of big companies, than Americans do. So there remain some real issues to deal with regarding women in leadership.

Golbeck: You noted an implicit bias of how men should look to appear presidential. The number of women in upper levels of leadership is unbelievably small [13]. Do we have a conception of how women should look to appear presidential?

Jewell: Well, we haven't had a woman president in the US yet and Berkeley has never had a woman chancellor, so we don't really have a conception. Presumably Margaret Thatcher is what a woman prime minister "should" look like! 
Golbeck: Mary, what are some specific examples of the effects of implicit bias on the advancement of science?

Gray: Statisticians and mathematicians are key players in a lot of studies in science. A lot of times bias gets reflected in things that we get parts of. For example, it used to be that clinical trials only had males as the subjects, and nobody thought anything about this. You can obviously see that there is likely to be a different result if you had both men and women. It was the women scientists at NIH who agitated until the rules got changed to include women in clinical trials, and this change to include women has extended to a lot of other research that's being done.

I have a number of other examples just from the class that I teach on survey sampling. We did a project last fall during the national elections that involved whether or not people could vote, because they either had or didn't have voter ID's in the state of Virginia. One of my students said: "But you know, everyone has an ID, how can you fly without an ID"? Well, American University is the kind of institution where most people have the resources for air travel, and the student's concepts were limited to that reality. This isn't sex bias, but it is definitely a kind of bias.

In another semester, my students were going to do a study to determine whether foods that were healthy cost more than foods that weren't, and therefore people were not eating properly. They did surveys in various parts of Washington DC. Their results showed, contrary to their assumptions, that people were paying much more for food that wasn't healthy than they were for the food that was. Why did this happen? Because the young woman who organized the survey was a vegetarian, and she totally neglected the effect of the price of meat in the total cost of groceries.

So you can see there are all kinds of things that can be influencing science more generally, not just whether you get a job, whether your pay is equal, or whether you get to be president of a university.

Golbeck: Arlene, it has been shown that it isn't just people who have implicit biases. Even clever datamining algorithms can inherit implicit bias [19]. Can we use computerized algorithms to reverse-engineer bias?

Ash: We had a lively pre-panel exchange, finding and sharing many interesting articles. A recent one in the Washington Post described how researchers at Carnegie Mellon University studied Google's algorithm for placing job ads in front of people whose search history suggests that they might be interested in them [6]. Of course, Google won't tell you how its job ad-placing program works, but the Carnegie Mellon "Ad Fisher" team devised a test to see how it performed in placing these ads.

The program created thousands of different accounts. Each simulated the web-search behavior of one "simulated person" looking for a job. The machine created the same search history for simulated individuals who differed only by sex. The results showed over 1500 "men" but only 300 "women" received ads for high paying, high prestige jobs.

Of course, a sophisticated algorithm would seek to place ads based on the fraction of similar placements that had been "successful" in the past. Maybe women have less often clicked on such ads; or maybe employers advertising such positions have rarely offered such jobs to women. Whatever the underlying mechanism, such algorithms instantiate, perpetuate, and potentially amplify our society's prejudices. Google has a "bias busters" internal team. I hope that they can figure out how to deal with this algorithmic bias.

We can all learn from the example of the NIH Common Fund's High-Risk, High-Reward Program, which found that a search for "risk-takers" nets fewer women than one seeking "innovation" and "creativity" [5]. When looking for leaders, let's avoid sending signals that artificially limit the pool of potential talent.

\section{What has been the effect of all the attention to so-called 'implicit bias'?}

Golbeck: There has been a lot of attention to these issues both in organizations and the media. An example is the popular book, Blink: The Power of Thinking Without Thinking [9]. One effect is more attention is being given to the neuroscience of implicit bias. I'm talking about the fMRI-based studies that are the subject of another popular book, How Your Unconscious Mind Rules Your Behavior [20]. fMRI stands for functional magnetic resonance imaging. This technology is a research tool that psychologists are using to combine MRI and behavioral data. This powerful combination is allowing us to learn more about some extremely difficult subjects like prejudice and stereotyping.

Now let's turn to some of the effects of implicit bias that our panel would like to talk about. Mary, in your experience, what has been the effect?

Gray: I don't actually think there has been very much effect. I think it's been distracting. You are going to hear about how things have improved in various 
organizations. But I've been on panels and committees over many years, and there is always some reason why results of studies don't get implemented. Either there is not enough money, or you didn't consider enough variables, or you didn't have a good sample, or something else was wrong.

The same is true with the implicit bias, where there is a lot of research about what so-called implicit bias is supposed to do. But my feeling is it is just a distraction, and it keeps people from getting down to the nitty gritty of what is the actual impact of the bias. It's back to the notion that we have in the law: What's been the effect of this, and what would change the effect? Just talking about it is not good enough.

Golbeck: We are seeing a small but growing body of research literature now that illuminates some of the effects of implicit bias. Marcia, how are you using some of this literature in your institution to try to change the effects of implicit bias on faculty searches?

Gumpertz: Many universities across the country, in particular many that have had NSF ADVANCE grants, have started training faculty search committees on diversity and the effect of implicit bias. I want to tell you about two studies that we use at North Carolina State University in facilitated discussions with faculty, so people on search committees can start to think about how this might come into play in faculty searches.

One of the studies was done about 12 years ago [4] The researchers looked at 1,300 applications for jobs in Chicago and Boston. These were jobs in sales and clerical service-type occupations. The researchers made up a bank of resumes based on real resumes and submitted four resumes for each job ad: They assigned an African-American-sounding name to two of the resumes, and a white-sounding name to the other two. They submitted these resumes, and then they counted how many call-backs each resume got inviting them for an interview. For the white-sounding names, they had to send about 10 resumes before they got a call-back; for the African-American-sounding names, they had to send 15 resumes.

The other study was done more recently and in an academic setting [21]. You might think things are changing enough that this kind of thing isn't happening any more, but it is. Also, you might think that university faculty wouldn't fall into this kind of bias in looking at resumes, but they do. In this study there wasn't actually a job. The researchers made up one resume from an undergraduate student aspiring to go to graduate school. The student was applying for a supposed job as a lab manager. The researchers sent the resume to 127 faculty members in the sciences and asked them for feedback on the resume. Their cover story was that they were developing a mentoring program, and they wanted feedback to help them develop the program. For half of the requests for feedback they put the name John on the resume, and for the other half they put the name Jennifer. Same resume. For every measure of faculty feedback - hireability (would you hire this person), competence (how competent do you think this person is), and mentoring (would you mentor the person) - the male candidate got higher scores than the female candidate. When asked how much they would be willing the pay the person, the faculty respondents said they would offer $\$ 5,000$ more to the male candidate than to the female.

Golbeck: So we have research that has found evidence for effects of implicit biases in job searches, and this research can be used to try to make search committees more aware. Judy, what other decision-making bodies in our organizations need to be made aware of the potential effects of implicit biases?

Singer: I don't use the phrase "search committee training". Most Harvard faculty members don't want to be "trained", nor do they think they need to be "trained". We've taken a somewhat different tack. Instead of presenting topics like implicit bias in a "training" context, we present them in the context of "here are some interesting things about yourself about which you might not be aware".

I am privileged to have Professor Mahzarin Banaji, one of the developers of the concept of implicit bias, as a close colleague. She also serves as the senior advisor to the Harvard University Dean of the Faculty of Arts and Sciences on these issues. We recommend every faculty member take an Implicit Association Test (IAT). I highly recommend that you visit the "Project Implicit" web site [3]. The IATs are little timed tests. The first one takes about 10 minutes. They're designed to help you learn, in the privacy of your own home or office, whether you might actually hold some implicit biases. They cover a wide range of topics, including race, gender, sexuality, and religion. Try taking one. If the first one doesn't reveal a bias, take another one. I can guarantee you'll discover some biases you don't think you have. We're all biased. We all think we're fair, but we're all biased. And we've found that faculty members are fascinated by the cognitive dissonance that taking the IAT creates.

In preparation for this session, I took an IAT earlier today so I'd have the feeling fresh in my mind. I've taken a lot of these over the years, and I'm sup- 
posed to be the person at Harvard who has overcome this! Sadly, I was two standard deviations below the mean (but I won't tell you on which dimension). It's a little depressing when you find you're confronted with something about yourself that you can't believe is true. Most of us don't want to be prejudiced. But when you find yourself confronting behavior at odds with your beliefs, it gets you thinking that maybe your judgments can be clouded. With that, faculty become interested in learning about better ways of conducting faculty searches, about being more explicit and structured about criteria. If you could blind search committee members to the demographics of the candidates and obviously you can't, but if you could - there's lots of evidence that suggests that it would make a difference. So I think there is a lot of work we can do without using the word "training".

We've also found that faculty aren't necessarily skilled at some of the organizational behavior skills needed to chair a search committee (or to be a committee member). So we've developed a relatively short 18-page guide on Best Practices for Conducting Faculty Searches [22]. It includes a special pullout section on implicit bias, but it also devotes a lot of attention to how to run (and participate in) effective meetings. I knew I was onto something when a member of the Harvard Corporation (who is the CEO of a major company) said, "This is really useful! I spend my life running meetings and I haven't thought about some of these things". So we teach colleagues not just about implicit bias but also how to run an effective meeting, how to listen to different voices, and how to prevent the grand poobah from dominating the discussion with pronouncements like "I'm sure you all agree that $\mathrm{X}$ should get the job". Implicit bias is a major issue but it's not the only area in which we need to improve. Many faculty members are quite intimidated by the process of chairing a meeting of their colleagues and they welcome help about these very practical matters.

The second thing I would say is that I think leadership makes an enormous difference. I'm fortunate that the current president of Harvard University is Drew Faust. She has been president for the last eight years. My prior president was Larry Summers, who famously made some comments about women in science. It was a very hot topic on the Harvard campus, which catalyzed energy on the campus and led, in part, to the creation of my office. That was a very concrete leadership response.

Deans can also make a huge difference. I've seen what happens when a dean says to a department chair during a tenure review: "Is there any possibility that your judgment might be clouded by implicit bias"? All of a sudden implicit bias gets talked about back at the department. So leadership makes an enormous difference, and if you can talk to your department chairs, deans, provosts, and presidents, and raise this issue, perhaps using sample letters like the ones I read earlier, you might start to convince people that implicit bias may cloud people's judgments.

Golbeck: Arlene, you work in a medical school, and medical schools can be different environments. What's happening in your medical school in relationship to implicit bias?

Ash: I'd like to further address the tension that Mary discussed: Making people aware of their implicit biases is only useful if it leads to more diversity in places like medical schools and, more generally, developing every individual's potential. Our school does encourage students to take the implicit association tests, and some people push back: "That doesn't mean that I'm prejudiced". But the discussions raise important issues that our students might not normally think about. And many - even those who don't think that they are prejudiced - say they think they will behave differently because of this training. And maybe they will.

In talking to the woman who is in charge of diversity efforts on our campus, and in interacting with this panel, I came away with several thoughts. One: where you sit, who you are, and what job responsibilities you have shape your ability to actually advance diversity. Our school is concerned that less than $2 \%$ of our faculty members are African-American. However, only $2 \%$ of the potentially available pool in academic medicine is African-American. So improving our "race numbers" in today's world means stealing somebody from another school; this "zero sum game" is not particularly productive.

It's important to figure out the particular diversity problems and opportunities that you face. Sometimes you have a pipeline issue (too few people in the applicant pool), and sometimes a different issue (such as not doing a good job of nurturing and advancing the careers of people where they are). Issues are different when selecting someone for a job or training opportunity, versus supporting someone who is already a member of your community. Not only does our school have very few African-American faculty members, but our satisfaction survey suggests that we could do a better job of making those that we do have feel more welcome and supported.

Whatever your official role, you should strive to treat each individual well. Stereotypes can sometimes help 
alert you to the fact that a person might have a problem outside your experience. For example, Mary told us about a student who couldn't imagine adults who don't have a driver's license, or any other governmentsponsored ID. Yet $10 \%$ or more of Americans of voting age don't have such credentials.

Don't assume that you know what people's problems are. Try to learn what they need and how you can be of help. Stereotypes cause harm when they lead you to pre-judge people as a substitute for thoughtful and supportive interactions.

Golbeck: Jon, you were president of the ASA. Voluntary associations are different from the organizations we are employed in. What is our professional association, the ASA, doing about implicit bias?

Kettenring: Well, actually, I had no clue. So I asked our esteemed Executive Director Ron Wasserstein what the ASA was doing. I'm going to share his answer with you.

The ASA policy on implicit bias goes back to November of 2011. The board of directors adopted a policy very similar to one that was already in place by the Mathematical Association of America. The title is, "Avoiding Implicit Bias: Guidelines for ASA Awards Committees" [1]. So the focus at that time was on the awards component.

I think it's encouraging that the ASA has been using this policy in a broader sense. Ron made the comment to me that we're also applying it to appointments on committees. ASA President-Elect Jessica Utts sent me a note saying she was well aware of the policy, and she is keeping these concerns in mind when making her appointments for 2016.

Here are the 12 components of the policy [1]:

1. Appoint diverse selection committees and chairs.

2. Generate a large and diverse pool of nominees.

3. Publicize the award among underrepresented groups.

4. Periodically review and discuss practices for building a pool of nominees.

5. Periodically review the description and guidelines for the award.

6. Discuss the process and criteria.

7. Consider those with strong qualifications but whose work may be less widely known.

8. Make a personal list of top nominees. [This avoids the undue influence of one member and insures that the list of viable nominees is as large as possible before discussion begins.]

9. Create short lists via inclusive methods.

10. Ensure every committee member's voice is heard.
11. Take adequate time to make a decision.

[This reminds me again of the book, Thinking

Fast and Slow. Take the time to do it right.]

12. Avoid conflict of interest.

I was pleased to see that there was a very thoughtful list here. Taking a list like this and adapting it to other contexts could help give you a running start on dealing with implicit bias issues in somewhat different contexts.

\section{What are specific success stories or best practices for achieving equal professional opportunity for all?}

Golbeck: One example of a success is the AAUP Higher Education Salary Evaluation Kit [27], conceptualized in the early 1970s when Mary Gray, our panelist, was chair of the AAUP Committee on Women in the Profession. UC-Berkeley Professor Elizabeth L. Scott developed the kit, and Mary helped oversee this effort. The kit influenced salary adjustments.

Let's take a look at what's happening now. Arlene, what are some specific success stories or best practices for achieving equal professional opportunity for all?

Ash: Many have studied this key question: What works to change people's attitudes and, ultimately, their behaviors? Sadly, most of what people have tried doesn't work. But at least we're doing research on how to do better.

There are a few notable success stories. Most don't pertain to our profession. One is how symphony orchestras are no longer all male, because auditions are held with people walking on in their socks (to eliminate the sound of walking in high heels), sitting down behind a screen, and playing [14]. Those who make the judgments have to do it simply on how the music sounds, without recourse to irrelevant information like the musician's height, weight, race or sex. Unfortunately, what makes for a good faculty hire is more nuanced and multidimensional - it can't be fully blinded. We know that the hiring committee should make a list of the key job requirements and tabulate the factual evidence as to how well each candidate's credentials fit those requirements, but - unlike a symphony orchestra - we cannot use a fully blinded process to eliminate our biases.

Some success stories do apply to professions like ours. For example, five or six years ago all of the panels and all of the speakers at the microbiology professional meetings were men, even though about half the 
microbiologists were women [17]. Then they changed the rules. On every committee putting together an invited session there has to be a woman; there has to be someone who pays attention to the gender makeup. In just a few years, they achieved equity.

So there are things we can do. We must go for the "low hanging fruit" and adopt process changes that have been shown to be useful. We must also continue to learn more about what strategies work, and continue to collect and report data that reveal the extent to which we are meeting our legal and ethical responsibility to treat everyone fairly.

Golbeck: Judy, what are specific success stories in convincing colleagues, leaders, and decision-makers that their judgments may also be affected by implicit bias?

Singer: There is an example about the Harvard statistics department, where I earned my PhD in 1983. The department was founded in 1958. There was a 58-year gap, but I'm very pleased to say that, as of Thursday, the Harvard statistics department now has two tenured women, biostatisticians Xihong Lin and Xiaole (Shirley) Liu who previously were appointed to the Harvard biostatistics department.

What changed? First, we have a committed dean who told the department that it could not conduct any searches unless they changed their ways. This requires honest conversations, something that can be hard to do. But if you don't have those honest conversations, people are going to keep thinking that what they are doing is just fine. Second, this dean appointed a new department chair who is committed to addressing their issues. His name is Neil Shepard. He was recruited to Harvard just three years ago. He was appointed department chair starting in September, but he's already done a number of things. He began by having honest conversations with his dean, with me, and most importantly with his departmental colleagues. They reviewed the lack of success in recruiting women. He was particularly concerned about their all-male search committees, which was inevitable if all the voting members of the department are male. Now that Lin and Liu have tenured appointments in the department - which means they get to vote on tenured appointments and can serve on search committees - I'm optimistic about the future.

The dean has now given the ok to do searches, and he's agreed that the department can make not just one hire, but several. Research shows that when you have to make decisions one by one they are much more likely to favor the white or, in the case of statistics, Asian man. If there is a cluster-hire, the committee is unlikely to come up with a pool of three white or Asian men. It wouldn't be acceptable and they know it. We've also rewritten the language for the ad to say, "The department is keenly interested in diversifying its faculty". This language is a sign that they want to do things differently. So a dean and a department chair can make a huge difference.

If your departments look anything like the Harvard statistics department for the prior 58 years (and the rosters of your departments indicate that some of yours do), then having these kinds of honest conversations and bringing the issues out into the open makes an enormous difference. Change is possible. Leadership is key.

Golbeck: Judy, Harvard didn't appoint a man and a woman this year, they appointed two women. Why is it helpful to have two women brought in to the department?

Singer: When you're the only woman in the room, often times you don't get paid attention, sometimes you're asked to bring the coffee, a number of things happen. So having two women makes an enormous difference. You're not alone. You don't necessarily have to see eye to eye with the other woman, but you're no longer a token. Of course, having more is also better: two is better than one, but three is better than two.

Golbeck: Then what happens when women lead or take responsibility, Mary?

Gray: Better things happen than when they don't. That doesn't mean good things always happen. If you have women in leadership positions, they're sometimes as insensitive to the issues as men, either because they just don't see them, or because they have a so-called Queen Bee complex: "You know, I like being the only woman, I'm so much better than the rest of the people who are the worker bees, and I'd like to keep it that way". So you can't count on women doing better. But the importance of there being more than one minority person in a group has been shown with a lot of jury research, where when you only have one person on a jury who is holding out, it is very difficult to be heard. If you have two it's much easier. Now obviously if you have three it's easier still.

In fact, there is a lot of research on what constitutes a sufficient cluster to make a difference. For example, in the affirmative action lawsuit at the University of Texas at Austin, which is now at the Supreme Court once again, the issue is: How many minorities do you need to get at the university in order for them actually to have an effect? We'll see what the court says this time, because you can't count on the Supreme Court either. 
But, that's another way women take leadership. Maybe we would be unhappy in the case of Texas because it is a woman who sued Texas, but there have been some very important reforms based on a woman suing. We've had pension reform because a woman, Natalie Norris, allowed herself to be discriminated against just long enough to file suit. Lilly Ledbetter is another example where the law got changed. These things happen.

You can see some changes. I worked on the committee that came up with the 12 statements on implicit bias for the ASA that Jon presented. We worked very hard to come up with the statements. The excuse that the ASA used for the underrepresentation of women among research award winners is one many organizations use: All of these awards committees are different committees. There are seven different research awards given by ASA. Each one has a separate committee. So it doesn't seem to them that bad that they come up with men all or almost all of the time. But when you put together the effects of all of these committees, then you see the total effect. Part of the solution was supposed to be not only that the new policy was going to be followed, but that there would be an oversight awards committee that would meet with the people who were on the other awards committees and see that we got more equity. At one JSM, I gave a presentation to the awards committee about why this was important. I wish I could say I made a great impact, and we then suddenly had lots more women getting research awards. That's probably not the case.

The one thing that I think is really effective in scientific organizations is the thing Arlene mentioned about the microbiologists. When you get a woman to organize the panel, you are much more likely to get women on the panel. Simply increasing the number of women who are doing the invited panels or sessions, or who are doing an activity where you have to choose other people, is something that has managed to work. So that's something I can recommend to everyone, whether it is a solution to the problem of implicit bias or not. And when Harvard manages to get women into tenured positions in the math department, then I'll believe they've solved the problem!

Singer: I didn't say I had solved the problem! We had one woman in mathematics. She was recruited to Princeton to become the first woman in their math department.

Gray: And then she moved again.

Singer: Yes, this is what happens. Faculty members get poached. The market for top talent is absolutely crazy.
Earlier we were talking about the gender imbalance in the distribution of ASA awards. One way to solve this imbalance is to ask committees to nominate several outstanding candidates, not just one. Ask each committee to nominate three potential recipients and then all the committee nominations go to a central oversight committee. All the committees are unlikely to nominate three white or Asian men, especially if you bring the gender imbalance to their attention. And if all seven awards committees do, then the problem is much more serious and needs a more major intervention.

Golbeck: Talking about serious problems, pay inequity is a persistent serious problem. Nick, you have spent a lot of time thinking about pay equity.

Jewell: There was a very interesting article in The New York Times about five years ago illustrating levels of pay inequity in various professions [8]. Some professions display serious pay inequities. The problem gets much worse the higher the median salary; if you're a woman, you're going to tend to do much worse relatively speaking as you get promoted. That's the reality.

The article shows there are two professions where women get paid more 'on average' than men: Special education teachers and postal clerks. Women do equally badly in academe and law: Women professors and women lawyers both get paid $20 \%$ below men.

Aren't universities supposed to be progressive? Aren't all university faculty members supposed to be socialists? So how can this happen? In reality, universities are one of the most conservative professions on the pay issue. Every one of you who work in a university will go to work next Monday in an institution which is exploiting women every single day at least in terms of their pay. It's a fundamental problem.

President John F. Kennedy signed the equal pay act in 1963. That was 52 years ago. The modern version of this act is the paycheck fairness act. It states that women should get equal pay for equal work. This act has been blocked in Congress in 2010, 2012, and 2014. It hasn't even come up for a vote. I hope we're successful in 2016, but since 2016 is a presidential election year, it's probably not going to happen.

So what can we do? The first thing is to be active 'politically', because then things will change. If you're not political about anything, choose something to be political about. Locally, do a pay equity study. Just do one in your department. You can usually get this information. In my institution, it's on the web. Or ask your dean or your chair to do a pay equity study. Demand it. In fact, there are laws that obligate institutions to do pay equity studies. And you're also obligated by law 
to do something about it if you determine the existence of a pay gap. So the way to get something done is to actually start the process.

Because we are statisticians, we can provide tools. You've heard about Betty Scott's AAUP tools for conducting salary equity studies. Provide the tools to chairs and deans so they can identify inequities. Many people are determining salaries as part of their jobs, and they are not looking at the data systematically. They are doing the 'every single act separately' rather than looking at the groups. When you're looking at salaries as a whole in a department or a college, you see the inequities more clearly. You've got to keep challenging the status quo.

Women have to raise their voices and take action. But women shouldn't be the only ones: Men should raise their voices and take action, too. The pay situation is unacceptable. This is a moral issue that women are not being paid equally. There are other things about part time labor and flexibility in the workplace for women that are similarly very important.

Golbeck: Nick, do you want to say something about gated communities?

Jewell: The term 'gated communities' makes us think of all these country club places where people live. The term was coined by sociologist Robert HironimusWendt in a broader sense. Some academic disciplines are gated communities. Let me explain.

A new study at UC-Berkeley ranked every department by the fraction of their faculty that are women [23]. Mechanical engineering has the highest fraction of male faculty, followed by electrical engineering, computer science, physics, economics, and mathematics. Statistics is ranked 14th. The women are teaching all of the wonderful arts that are so important and vibrant for any university. Art history, Spanish and Portuguese, theater/dramatic performance, art, and film and media have the highest fraction of female faculty.

There is no reason why men and women should have equal interests. But who gets paid the most? It's the mechanical engineer, not the art history professor. Why is that, and why is average faculty pay so correlated with the ranking? Well, you could argue, maybe the mechanical engineers are more important because they build bridges, and so they are more important to society; art history doesn't contribute much to the economy. Is this really the only reason behind the noticeable pay variation?

These pay equity reports come out, and people explain them away. For example, they say that we ought to stratify on department or discipline. If you leave economics in a social sciences gender comparison and don't adjust for it, the imbalance is usually huge. Economists get paid far more than anyone else in the social sciences, and they are almost all men. So people take economics out of the social sciences comparisons, and then they say: That's better now, there is less inequity.

But is it really better? Perhaps women are being blocked from being economists, systematically. It's a gated community. Who lets you into the economics department where the salaries are big? The economics department lets you in. Who are the economics department? They're predominantly men. So some disciplines are essentially gated communities. I think it's not enough to require that in the French department a man and woman should be paid the same and stop there. I think we should have comparable pay for comparable work. Professors do the same job, pretty much, if they're in the French department or the statistics department, and we ought to get away from this idea that certain professions are very highly paid at the same time making them almost exclusively male.

\section{How can you start a conversation about diversity in your organization?}

Golbeck: In order to effect change, it's important not just to start, but also to sustain conversations about diversity in our organizations. Arlene mentioned that what you would do depends upon your vantage point. One of the things I was able to do when I worked at the higher education system level in Kansas was to stimulate diversity through the department chairs at the seven state universities. Kansas had an annual statewide higher education conference on diversity and multiculturalism. The state also had an annual statewide professional development conference for university department chairs. The university provosts and I got together, and we said: "This Michael Tillford Conference on Diversity and Multiculturalism, it seems like the same people go every time and we are preaching to the choir. Maybe we should devote the department chairs conference to diversity this year". And we did. We focused on the role of the department chair as a diversity agent. We didn't want the effort to end with the conference, so we asked the department chairs to formulate action plans that they would take back to their campuses. That was all done in the presence of the department chairs' deans and provosts. It was something we were able to do at the system level.

There are all kinds of things happening now on our 
campuses and in our organizations. Let's see some examples of what has been done from those vantage points. Marcia, how can you start a conversation about diversity in your organization?

Gumpertz: I think having discussions about diversity is key to change. People need to engage with these ideas. It's not something that statisticians or people in professional organizations or university departments usually talk about, or think is part of what they should be talking about, so it might be hard to get the discussion started. But it's important, because in a university department, faculty are the ones who make the hiring and admissions decisions. People in the department or unit set the climate for everyone there. So it's really important to have a way for people to start thinking about these ideas.

I have a few thoughts about how to get discussions started. With statisticians, data are very powerful: Showing trends, demographics, results of climate studies, results of any salary equity studies, etc. These results are a great way to get the discussion started.

You may find that it's helpful to have an outside facilitator come in and lead the discussion. People aren't used to thinking diversity is something that the organization needs to talk about, or people are afraid of saying the wrong thing. There are barriers to talking about race, religion, gender, and all of these things. It's very tricky. So having a trained facilitator can be a good thing.

Another easy way to get faculty talking about diversity is to have a reading group about some interesting topic, like the use of SAT's in admissions for students. A book came out this summer, The Tyranny of the Meritocracy, which can generate lots of great discussion [16]. So a reading group is also a good thing.

It's important to be able to articulate the important questions for your organization. What things affect your mission that people will care about in your organization? This will help you get buy-in for having these discussions. At our physics department retreat this summer, I asked the faculty to anonymously send stories beforehand of things they had either experienced themselves, or students had experienced, or they had witnessed, or microaggressions they themselves had perpetrated. Then we had a session built around these stories. People were incredulous: This happened in our department? Knowing that the stories were from their own colleagues made it real to them and important to talk about. Everyone brainstormed in small groups about how you would handle different situations. If this came up in your class, how would you handle this? If this is going on in the department, what can we do as a department to change and prevent this kind of thing from happening again?

I think for academic groups, having discussions around topics from faculty's own experience is a really good way to start discussions. I also think that showing real data - not just from the whole institution or country, but from that department - is very effective.

Golbeck: Nick, briefly, how important is it to have men engaged in these conversations in all aspects and not leave the work to diversity committees and specified diversity representatives?

Jewell: I think it's very important to engage men in these conversations. I went to the recent Women in Statistics Conference. There were about three men and 600 women attending. I recommend the conference if it is done again. It was a very interesting experience for a man to be such an underrepresented minority; men almost never have that kind of experience. It's extremely important to have champions of change. Men run the world, unfortunately or fortunately, depending on your perspective. Men make the rules, and if you don't get the foxes involved in 'changes', the chicken house is going to get raided forever. We have to have men involved, and we have to challenge men to be champions of change.

Golbeck: Judy, what are some effective strategies for enlisting men (i.e., not "just" women) in being champions for change?

Singer: I'll start out with an anecdote. A number of years ago I was on a diversity committee at the university, and it was all women. At the end of the year, the chair of the committee asked, "What can we do to improve this committee next year"? I said, "Invite some men". One of the women on the committee said, "Why would we want to do that"? I looked at her and said, "That's what they used to say about having women on committees"!

I disagree with the notion that diversity work should be done solely by women and minorities. Fortunately, there are now generational shifts. Look to some of your younger colleagues, who are more likely to be concerned about these issues. Younger men were brought up in a different generation. I've been doing events for recently tenured faculty. The men are keenly interested in gender issues. They don't want to be in departments that misbehave anymore.

Expertise also matters. Reach out to the social scientists on your campus. Some of what we've been discussing is standard social psychology and behavioral economics; reach out to your colleagues in those departments. You undoubtedly have local experts who can be effective champions on this point. Bring in out- 
side people to talk and get a conversation going on your campus.

Push for gender-neutral family-friendly policies. We want all of our faculty members to be able to balance work and life, not just the women. This will make it better for everybody.

Our recent Harvard faculty climate survey included two standard items that I'd like to mention [31]. The first is: Does your school or department make genuine efforts to recruit female faculty? We found that women are three times as likely to disagree with the statement. The other item is: "I feel the climate for female faculty in your department is as good as it is for male faculty". We found women are twice as likely to disagree. When men see these results, it's hard to argue that everything is fine, and it really becomes quite compelling.

We also looked at data on time use for our tenure track (junior) faculty. Instead of just looking at gender differences, which is what typically has been done, we broke it out by family household composition: No partner or children; partner, no children; children and nonworking partner; and children and working partner or single. We found no significant difference in hours at work for men and women in any of these categories. For women and men who don't have children and don't have partners, we found indistinguishable differences in hours on household duties. We did, however, find a 20-hour gap in the amount of time spent on housework and family responsibilities for the category of people with children and working partner or single. The men are actually doing more - they're doing 20 hours a week on average - but the women are doing 40 hours a week on top of their average 60-hour work-week. In retrospect, I'm sorry I didn't ask about how many hours they sleep and what kinds of leisure activities they pursue!

These results have catalyzed conversations. They've been picked up in newspapers and also in our departments, where colleagues are saying: I didn't actually realize that our female faculty members with children effectively have another full time job at home.

Gray: I want to bring up one thing about how to start conversations. You probably can't see, but I'm wearing a 3/4 of a Euro pin that a group of feminists gave me when I was at a conference in Helsinki about an opera by a woman composer and woman mathematician. Three quarters of a Euro is what the average salary is for women in Europe compared with men. (And I'm having one made with the Sacagawea dollar!)

Golbeck: Jon, briefly, what are some of the measurement issues?

Kettenring: Actually, there's been quite a bit of discussion about measurement issues. It's pretty clear we know how to count things, and we know how to take a look at the numbers and assess their strengths and weaknesses. However, the more I've thought about this question, the more it seems to me that some of the things we really want to measure are pretty difficult. I've looked at a lot of the literature. I don't find much encouraging there. But it doesn't mean we should give up. It just means we should recognize that, for example, just because we have a few women on the faculty, that's not the end of the story. There are a lot of deeper issues that we all are aware of, I think, that are hard to quantify. It reminds me of a statement that Deming used to make a lot about complicated situations [7]: The things we really want to know are unknown and unknowable. But we shouldn't give up because of that.

\section{Conclusion}

Golbeck: Implicit bias affects decisions to pursue career tracks [25], and it affects levels of success within careers [34]. John Lennon famously once said in an interview that every child is an artist until he's told he's not an artist. Arlene, what happens in life to some of our creative talents?

Ash: The bulk of Pollack's book describes the multitude of ways in which her incredible talent, drive and determination to become a physicist was ultimately overcome, and her reflection and research on why that happened, and what has and hasn't changed since she was in school. The larger point of these various threads is that our society frequently fails to nurture, and often actively discourages, the creative talents of many, many people.

Golbeck: Mary, you've had so many years of experience in this whole area of gender equity. Do you have any concluding remarks?

Gray: The conversation needs to get started, and you need to be persistent. Sometimes it makes you unpopular. I don't think we talked about that, but it can happen. People don't always like to have things pointed out for which they are responsible and probably should not have done. But you need to stick with it. You need to be persistent. And you need to involve men. One of the things I've found is that men suddenly become much more interested in these problems when their daughters are job-seeking age. But get them started a little bit earlier than that. You need a lot of allies.

Golbeck: We asked ourselves two basic questions when we decided to propose this JSM session. (1) Can 
the statistics profession afford to have unintentional perceptions continue to hinder the success of women and other underrepresented groups in statistics? (2) Is it reasonable for our profession to continue to underuse its human capital toward the advancement of science? As our good colleague Dan Solomon points out, diversity in the workplace isn't just an issue of ethics; it is also an economic, academic, and business imperative [32].

\section{Acknowledgments}

The authors wish to thank Fritz Scheuren for inviting us to prepare the content of our JSM Invited Session for publication. Amanda Golbeck wishes to thank the Waterman Fund of the Philadelphia Foundation for its support of the Elizabeth L. Scott Projects.

\section{References}

[1] American Statistical Association (ASA), Avoiding Implicit Bias: Guidelines for ASA Awards Committees, Accessed on 11/16/2015 at http://www.amstat.org/awards/acguidelines. $\mathrm{cfm}$.

[2] Association for Women in Science (AWIS), Implicit bias in STEM. Accessed on 11/12/2015 at: https://awis.site-ym.com/ ?Awards_Outcomes.

[3] M.R. Banaji and A.G. Greenwald, Blindspot: Hidden Biases of Good People, Delacorte Press (2013). See: https://implicit. harvard.edu/implicit/.

[4] M. Bertrand and S. Mullainathan, Are Emily and Greg more employable than Lakisha and Jamal? A field experiment on labor market discrimination, American Economic Review 94(4) (2004), 991-1013.

[5] M. Carnes, S. Geller, E. Fine, J. Sheridan and J. Handelsman, NIH Director's pioneer awards: Could the selection process be biased against women? Journal of Womens Health 14(8) (2005), 684-691.

[6] J. Carpenter, Google's algorithm shows prestigious job ads to men, but not to women, Here's why that should worry you, The Washington Post, 6 July 2015.

[7] W.E. Deming, Out of the Crisis, The MIT Press, 2000.

[8] H. Fairfield and G. Roberts, Why is her paycheck smaller? The New York Times, 18 May 2010. Accessed on 10/11/15 at: http://www.nytimes.com/interactive/2009/03/01/business/ 20090301_WageGap.html?_r=0.

[9] M. Gladwell, Blink: The Power of Thinking Without Thinking, Back Bay Books, 2007.

[10] A.L. Golbeck, Where are the women in the JSM Registration Guide? AmStat News 421 (2012), 16-17.

[11] A.L. Golbeck, Equivalence: Elizabeth L Scott at Berkeley, Chapman \& Hall/CRC Press, forthcoming.

[12] A.L. Golbeck and C.A. Molgaard, Professional awards in statistics: Chipping away at gender disparities in the USA, Proceedings of the $59^{\text {th }}$ International Statistical Institute World Statistics Congress, Hong Kong, China, 2013, pp. 5155-5160.
[13] A.L. Golbeck, I. Olkin and Y.R. Gel, eds, Leadership and Women in Statistics, Chapman and Hall/CRC Statistics Press, 2016.

[14] C. Goldin and C. Rouse, Orchestrating impartiality: The impact of "blind" auditions on female musicians, American Economic Review 90(4) (2000), 715-741.

[15] M. Gray, Leadership and the legal system, in: Leadership and Women in Statistics, A.L. Golbeck, I. Olkin and Y.R. Gel, eds, Chapman and Hall/CRC Press, 2016, pp. 229-244.

[16] L. Guinier, The Tyranny of the Meritocracy: Democratizing Higher Education in America, Beacon Press, 2015.

[17] S. Jaschik, Ending all-male panels, Inside Higher Ed (5 August 2015), Accessed on 11/16/2015 at https://www. insidehighered.com/news/2015/08/05/microbiologists-showits-possible-achieve-gender-equity-scholarly-presentations\#. VcIcOGe3Nqs. mailto.

[18] D. Kahneman, Thinking, Fast and Slow, Farrar, Straus and Giroux, 2013.

[19] C.C. Miller, Algorighms and bias: Q and A with Cynthia Dwork, The New York Times, 10 August 2015. Accessed on 9/2/2015 at http://mobile.nytimes.com/2015/08/11/upshot/ algorithms-and-bias-q-and-a-with-cynthia-dwork.html.

[20] L. Mlodinow, Subliminal: How Your Unconscious Mind Rules Your Behavior, Vintage Books, 2012.

[21] C.A. Moss-Racusin, J.F. Dovidio, V.L. Brescoll, M.J. Graham and J. Handelsman, Science faculty's subtle gender biases favor male students, Proceedings of the National Academy of Sciences 109(41) (2012), 16474-16479.

[22] Office of the Senior Vice Provost, Best Practices for Conducting Faculty Searches, Harvard University, 2016. Available for download at www.faculty.harvard.edu/FacultySearch.

[23] Office of the Vice Provost for the Faculty, Report on the UC Berkeley Faculty Salary Equity Study, January, 2015, p. 16. Accessed on 10/11/2015 at: http://vpf.berkeley.edu/sites/ default/files/Equity\%20Study\%20Report\%20final\%201-26$15 \% 20$-revised. pdf.

[24] Ohio State University, Kirwan Institute for the Study of Race and Ethnicity, 2015. Accessed on 11/12/2015 at http:// kirwaninstitute.osu.edu/.

[25] E. Pollack, The Only Woman in the Room: Why Science is Still a Boy's Club, Beacon Press, 2015.

[26] D.L. Sackett, Bias in analytic research, Journal of Chronic Diseases 32 (1979), 51-63.

[27] E.L. Scott, Higher Education Salary Evaluation Kit, AAUP, 1977.

[28] E.L. Scott, Letter to NSF fellowship program officers, Eliza beth L Scott papers, Bancroft Library, UC-Berkeley, 1984.

[29] K. Servick, Forensic labs explore blind testing to prevent errors, Science 31 (July 2015), 462-463.

[30] J.M. Sheltzer and J.C. Smith, Elite male faculty in the life sciences employ fewer women, Proceedings of the National Academy of Sciences 111(28) (2014), 10107-10112.

[31] J.D. Singer, Fostering the advancement of women in academic statistics, in: Leadership and Women in Statistics, A.L. Golbeck, I. Olkin and Y.R. Gel, eds, Chapman and Hall/CRC Press, 2016, pp. 413-428.

[32] D.L. Solomon, If you would consider a woman..., in: Leadership and Women in Statistics, A.L. Golbeck, I. Olkin and Y.R. Gel, Chapman and Hall/CRC Press, 2016, pp. 395-411.

[33] L.M. Wah, The Color of Fear (video), Stirfry, 1994.

[34] J. Wolfers, Even famous female economists get no respect, The New York Times (11 November 2015). Accessed on 11/ 16/2015 at http://www.nytimes.com/2015/11/12/upshot/evenfamous-female-economists-get-no-respect.html. 